\title{
Uma questão de gênero: onde o masculino e o feminino se cruzam *
}

\author{
Amícar Torrão Filho**
}

\section{Resumo}

Este artigo discute a importância dos estudos de gênero para a história, recuperando algumas de suas principais discussões e revendo o seu aparecimento na historiografia da segunda metade do século XX. Procura, ainda, inserir a construção da masculinidade como processo correlato da determinação da identidade feminina, e discute a questão da homossexualidade como parte integrante da construção da misoginia.

Palavras-chave: Gênero, Historiografia, Masculinidade, Homossexualidade, Misoginia.

\footnotetext{
" Recebido para publicação em abril de 2003, aceito para publicação em abril 2004.

** Doutorando em História, IFCH-UNICAMP, Campinas-SP, Brasil. amilcartorrao@uol.com.br 
Uma questão de gênero

Gender Issue: Where Masculine and Feminine Meet

\begin{abstract}
This paper discusses the importance of gender studies for history, recovering some of its most important discussions and reviewing their appearance on the historiography in the second half of the twentieth century. It searches to include the construction of masculinity as a correlate process of the determination of feminine identity, and it discusses the issue of homosexuality as an integrant part of the construction of misogyny.
\end{abstract}

Key Words: Gender, Historiography, Masculinity, Homosexuality, Misogyny. 
Amílcar Torrão Filho

Senhor! Senhor!, tornou a gritar, ao concluir os seus pensamentos, "devo, então, começar a respeitar a opinião do outro sexo, embora me pareça monstruosa? Se uso saias, se não posso nadar, se tenho de ser salva por um marinheiro, Deus meu!", gritou, "que hei de fazer?" E com isso entristeceu.

Virginia Woolf, Orlando

Sou apenas uma mulher e lamento-o.

Margarida de Angoulême, rainha de Navarra

Inicio minha discussão sobre as questões de gênero com um texto de Joan Scott, cuja principal virtude é a de conceituar o gênero enquanto uma categoria útil à história e não apenas à história das mulheres. Ele pode lançar luz sobre a história das mulheres, mas também a dos homens, das relações entre homens $e$ mulheres, dos homens entre si e igualmente das mulheres entre si, além de propiciar um campo fértil de análise das desigualdades $e$ das hierarquias sociais.

Scott argumenta que o conceito de gênero foi criado para opor-se a um determinismo biológico nas relações entre os sexos, dando-lhes um caráter fundamentalmente social. "O gênero enfatizava igualmente $\mathrm{o}$ aspecto relacional das definições normativas da feminidade". ${ }^{1}$ Este aspecto relacional vem da preocupação de alguns de que os estudos femininos se centravam sobre as mulheres de maneira demasiado estreita, assim a noção de gênero daria conta de que as mulheres e os homens eram definidos em termos recíprocos e não poderiam ser entendidos separadamente.

Além disso, o gênero enquanto categoria de análise teria a vantagem de propor uma transformação dos paradigmas do conhecimento tradicional, não apenas acrescentando novos temas, mas também impondo "um reexame crítico das premissas

1 ScotT, Joan W. Gênero: uma categoria útil de análise histórica. Educação $e$ Realidade, vol. 16, n 2, Porto Alegre, jul./dez. 1990, p.5. 
Uma questão de gênero

e dos critérios do trabalho científico existente". ${ }^{2}$ Ao lado das noções de classe e "raça", gênero assinalava o interesse da historiografia em uma história que incluía os discursos dos "oprimidos", numa análise do sentido e da natureza desta opressão.

Em outro trabalho, Joan Scott discute a história da emergência dos estudos sobre a mulher: numa narrativa tradicional, diferente da que apresenta esta autora em seus trabalhos, a história das mulheres teria surgido nos anos 1960 , com o movimento feminista exigindo que a historiografia apresentasse a participação feminina na história, resgatasse suas heroínas e que explicasse a opressão patriarcal. Estava-se num momento no qual os historiadores desfrutavam de uma "estranha imunidade", "a de não pertencerem a nenhum sexo"3; tinha-se, então, que convencê-los a assumirem que eles o possuíam, e que isso era relevante. Nos anos 1970, a historiografia das mulheres teria se afastado da política, com a ampliação do campo de questionamento e o surgimento de controvérsias internas e de autoridades intelectuais no tema. Nos anos 1980, teria havido o rompimento definitivo com a política, com o surgimento do termo gênero, aparentemente neutro, desprovido de propósito ideológico imediato.

A emergência da história das mulheres como um campo de estudo envolve, nesta interpretação, uma evolução do feminismo para as mulheres e daí para o gênero; ou seja, da política para a história especializada e daí para a análise. ${ }^{4}$

Para Scott, esta interpretação foca os estudos de gênero na história das mulheres, ou vê a emergência do gênero como um

2 ID., IB., p.6.

3 Woolf, Virginia. Orlando. São Paulo, Abril Cultural, 1972, p.334

4 ScotT, Joan. História das mulheres. In: BURKE, Peter. (org.) A escrita da história: novas perspectivas. São Paulo, Unesp, 1992, pp.64-65. 
Amílcar Torrão Filho

sinal de "despolitização", ou de "neutralidade". Para ela, esta narrativa

necessita de alguma reflexão crítica, não apenas por não ser tão simples, mas também porque representa mal a história da história das mulheres e seu relacionamento, tanto com a política, quanto com a disciplina da história. ${ }^{5}$

No entanto, mesmo reconhecida pela academia, a história das mulheres passou a ser entendida muitas vezes como um assunto de mulheres, mais especificamente de feministas, ou como uma história que diz respeito aos aspectos privados da casa, da família, da reprodução e do sexo, em oposição ao que realmente importaria à história, que é o domínio público da existência. A guerra, a economia, a política e outros temas nobres não teriam assim nenhuma relação com as questões de gênero. Para Scott, essa visão da história das mulheres coloca um desafio teórico, que questiona:

Como o gênero funciona nas relações sociais? Como o gênero dá sentido à organização e à percepção do conhecimento histórico? As respostas dependem do gênero como categoria de análise. ${ }^{6}$

Lembra-nos ainda a autora de que gênero é usualmente utilizado como sinônimo de mulheres, e que houve em muitos estudos a substituição de mulher por gênero. Isso se dá pois gênero denota uma erudição e uma seriedade do trabalho,

que tem uma conotação mais objetiva e neutra do que "mulheres". O "gênero" parece se integrar na terminologia científica das ciências sociais e, então, se dissociar da política (pretensamente ruidosa) do feminismo. ${ }^{7}$

\footnotetext{
${ }^{5}$ ID., IB., p.65.

${ }^{6}$ ID., Gênero como categoria... Op. cit., pp.6-7.

7 ID., IB., p.7.
} 
Uma questão de gênero

Nesta interpretação supostamente "despolitizada" do gênero, ele não estaria filiado, a priori, a um questionamento sobre a desigualdade ou o poder, ou tomaria partido pela "parte lesada". Gênero "inclui as mulheres sem lhes nomear, e parece assim não constituir uma ameaça". ${ }^{8}$ Como veremos adiante, Scott propõe um uso do gênero muito mais abrangente, incluindo o homem $e$ a mulher em suas múltiplas conexões, suas hierarquias, precedências e relações de poder.

A autora discute três posições teóricas sobre os estudos de gênero. A primeira, uma tentativa feminista de entender as origens do patriarcado; a segunda se situa numa tradição marxista e busca um compromisso com a crítica feminista; e a terceira se divide entre o pós-estruturalismo francês $e$ as teorias de relação do objeto, inspira-se em diversas escolas da psicanálise para explicar a produção e a reprodução da identidade de gênero do sujeito. ${ }^{9}$

Cada uma delas tem suas deficiências para esta autora: a teoria do patriarcado não mostra como a desigualdade de gênero estrutura as demais desigualdades, as marxistas estão muito presas à causalidade econômica $e$ não explicam como o patriarcado se desenvolve fora do capitalismo, além de haver, por parte do marxismo, uma tendência a considerar o gênero um sub-produto das estruturas econômicas cambiantes. Em ambientes universitários dominados pelo marxismo, informa-nos outra autora, nem mesmo

uma História da Mulher que fosse concebida como um estudo das lutas femininas pela igualdade de direitos políticos, sociais ou econômicos seria bem aceita na medida em que não estamos perante uma verdadeira classe social. $^{10}$

8 ID., IB.

9 ID., IB., p.8 e ss

${ }^{10}$ SILVA, Maria Beatriz Nizza da. A história das mulheres no Brasil: tendências e perspectivas. Revista do Instituto de Estudos Brasileiros (27), São Paulo, 1987, 
Amílcar Torrão Filho

Já algumas teorias pós-estruturalistas, ou a "teoria de relação de objeto", mais especificamente, fazem depender a produção da identidade de gênero e a gênese da transformação de estruturas de interação relativamente pequenas, além de limitar o conceito de gênero à esfera doméstica e da família.

Para incluir um pouco as preocupações teóricas das feministas brasileiras, lembro que Heloísa Buarque de Holanda, discutindo o mesmo tema, observa que o feminismo e a pósmodernidade trabalham com conceitos distintos e até opostos.

Enquanto as políticas e as teorias pós-modernas trabalham com as idéias da possibilidade do fim da história, do social, e do político, a crítica feminista insiste, contrariamente, na articulação de suas questões com as determinações históricas e políticas. Se os primeiros falam de uma crise da representação e da morte do social, o segundo fala exatamente de uma luta pela significação. ${ }^{11}$

Para Margareth Rago, o "desconstrutivismo" e o "pósmodernismo" vêm acrescentar à luta feminista e à crítica feminista da história, por denunciarem "uma racionalidade que opera num campo ensimesmado, isto é, a partir da lógica da identidade e que

p.76. O ambiente dominado pelo marxismo, a que se refere a autora, é o departamento de História da Universidade de São Paulo.

${ }^{11}$ HolANDA, Heloísa Buarque. Introdução. Feminismo em tempos pós-modernos. In: Tendências e impasses. O feminismo como crítica da cultura, Rio de Janeiro, Rocco, 1994, p.10. Em seguida a autora observa que, mesmo não sendo excludentes, os dois discursos apontam para campos diferentes de contestação, $e$ faz uma relação entre as teorias pós-modernas e as ideologias neoliberais, o que apontaria para uma nova forma de contestação, o pós-feminismo. No entanto ela observa que não se pode dizer que a ideologia neoliberal "encontre equivalência na prática política e na intervenção discursiva do conjunto dos diversos segmentos sociais 'minoritários', estando, portanto o feminismo longe de ter esgotado as potencialidades de seu ponto de vista crítico e político", pp.10-11. 
Uma questão de gênero

não dá conta de pensar a diferença". ${ }^{12}$ Tânia Swain, para quem os estudos de gênero trabalham a sexualidade, "tendo em vista a divisão binária do humano a partir das construções baseadas sobre o sexo", propõe uma ampliação do conceito de gênero para heterogênero, que proporia "um questionamento tão radical das relações sociais quanto o da teoria da construção dos gêneros, em sua época"13 , por dar conta da ambigüidade da sexualidade e das relações de gênero, que este conceito já não abarcaria no momento.

Voltemos a Joan Scott $e$ a sua própria definição de gênero. Para ela o gênero é "um elemento constitutivo de relações sociais fundadas sobre as diferenças percebidas entre os sexos, e o gênero é um primeiro modo de dar significado às relações de poder" ${ }^{14}$ Estas diferenças se fundam em símbolos culturalmente disponíveis que evocam representações simbólicas e mitos. Além disso, "os conceitos normativos que põem em evidência as interpretações do sentido dos símbolos, que se esforçam para limitar e conter suas possibilidades metafóricas", expressos em doutrinas religiosas, educativas, políticas ou jurídicas e que opõem

\footnotetext{
${ }^{12}$ RAGO, Margareth. Epistemologia feminista, gênero e história. In: PEDRO, Joana Maria e GROSSI, Miriam Pillar. (orgs.) Masculino, feminino, plural: gênero na interdisciplinaridade. Florianópolis, Ed. Mulheres, 1998, p.24. Sobre este debate ver nesta mesma coletânea os artigos de HEILBORN, Maria Luiza. Gênero: um olhar estruturalista, pp.43-55, e de CosTA, Claudia de Lima. O feminismo e o pós-modernismo/pós-estruturalismo: (in)determinações da identidade nas (entre)linhas do (con)texto, pp.57-90. Cf. Também BARBIERI, Teresita de. Sobre la categoría de género. Una introducción teórico-metodológica. In: AZERÊDO, Sandra e STOLCKE, Verena. (coords.) Direitos reprodutivos. São Paulo, Fundação Carlos Chagas/DPE, 1991, pp.26-45; SOIHET, Rachel. História, mulheres, gênero: contribuições para um debate. In: AGUIAR, Neuma. (org.) Gênero e ciências humanas: desafio às ciências desde a perspectiva das mulheres. Rio de Janeiro, Record/Rosa dos Tempos, 1997, pp.95-114.

${ }^{13}$ SwAIN, Tânia Navarro. Para além do binário: os queers e o heterogênero. Gênero. Revista do Núcleo Transdisciplinar de Estudos de Gênero, vol. 2, n 1 , Niterói, UFF, 2. sem, 2001, pp.93-94.

${ }^{14}$ ScotT, J.W. Gênero como categoria... Op. cit., p.14.
} 
de maneira binária e inequívoca as concepções de masculino $e$ feminino. ${ }^{15} \mathrm{O}$ gênero também tem um aspecto de identidade subjetiva, ao qual a psicanálise oferece uma teoria interessante de análise, ainda que a autora se diga cética com a sua pretensão universal. Para ela, ainda, os historiadores devem, antes de tudo,

examinar as maneiras pelas quais as identidades de gênero são realmente construídas e relacionar seus achados com toda uma série de atividades, de organizações $e$ representações sociais historicamente situadas. ${ }^{16}$

Até mesmo a cultura material, os objetos, as moradias, a organização espacial das cidades modernas, reflete e constitui as diferenças de gênero.

Os arranjos de mobiliário, o modo como são mobilizadas as qualidades ergométricas de determinados objetos da casa, a ornamentação dos objetos pessoais e domésticos, as regras de decoração, as especializações dos cômodos, a rotina doméstica $e$ os trabalhos que ela envolve, [todos eles são capazes de] produzir e reproduzir diferenças de natureza sexuada. ${ }^{17}$

A teorização do gênero também tem para Joan Scott uma segunda premissa:

o gênero é uma primeira maneira de dar significado às relações de poder. Seria melhor dizer: o gênero é um

\footnotetext{
${ }^{15}$ ID., IB.

${ }^{16}$ ID., IB., p.15.

${ }^{17}$ Carvalho, Vânia Carneiro de. Gênero e artefato: o sistema doméstico na perspectiva da cultura material. São Paulo, 1870-1920. Tese de doutorado, História, USP, São Paulo, 2001, p.15. Agradeço ao professor Edgar de Decca a indicação desta tese.
} 
Uma questão de gênero

primeiro campo no seio do qual, ou por meio do qual, o poder é articulado. ${ }^{18}$

A partir do gênero pode-se perceber a organização concreta e simbólica da vida social e as conexões de poder nas relações entre os sexos; o seu estudo é um meio "de decodificar e de compreender as relações complexas entre diversas formas de interação humana". ${ }^{19}$ Para Joan Scott, muitas relações de dominação da história, na Revolução Francesa, nos regimes autoritários, no conceito de classe estão ancoradas e se constituem na categoria do gênero, e para entendê-las é necessário entender o gênero. Ele ainda promove dentro da história a emergência de um "contradiscurso feminino", uma epistemologia feminista que

elimina [ou deveria eliminar] a preocupação de fortalecimento da identidade mulher, ao contrário do que se visava inicialmente com um projeto alternativo de uma ciência feminista. ${ }^{20}$

Pois o gênero se preocupa com a consolidação de um discurso que constrói uma identidade do feminino e do masculino que encarcera homens e mulheres em seus limites, aos quais a história deve libertar.

Entender o gênero para Scott significa também reconhecer que homem e mulher são "ao mesmo tempo categorias vazias e transbordantes, pois que, quando parecem fixadas, elas recebem, apesar de tudo, definições alternativas, negadas ou reprimidas". ${ }^{21}$ O gênero expõe, ainda, o dilema da diferença, a construção de desigualdades binárias, de diferenças pretensamente naturais, significa "lutar contra padrões consolidados por comparações nunca estabelecidas, por pontos de vista jamais expressos como

\footnotetext{
${ }^{18}$ ID., IB., p. 16.

${ }^{19}$ ID., IB.

${ }^{20}$ Rago, M. Epistemologia feminista... Op. cit., pp.28-29.

${ }^{21}$ ScotT, J.W. Gênero como categoria... Op. cit., p.19.
} 
tais". ${ }^{22}$ Uma diferença que deve se impor também na conceituação de gênero, na medida em que muitas vezes os termos mulher $e$ homem são utilizados enquanto categorias homogêneas e sem história, ou sem relação entre si. "Como resultado, a categoria 'mulheres' assumiu uma existência como entidade social separada de seu relacionamento conceitual historicamente situado com a categoria 'homens". ${ }^{23}$ Linda Nicholson propõe que, ao pensarmos no sentido do conceito mulher (e homem, acrescento), devemos entendê-lo como uma palavra "cujo sentido não é encontrado através da elucidação de uma característica específica, mas através da elaboração de uma complexa rede de características (...)". ${ }^{24}$

Um dos poucos aspectos não trabalhados por Joan Scott em seus textos é relacionado às fontes da história das mulheres. Aparentemente alijadas do mundo público, as mulheres não são notadas pelos escribas da história, e quando são notadas o são sob os mais freqüentes estereótipos:

mulheres vociferantes, megeras a partir do momento em que abrem a boca, histéricas do momento em que gesticulam. A visão que se tem das mulheres funciona como um indicador: elas são consideradas raramente por si mesmas, mas com freqüência como sintomas de febre ou de abatimento. $^{25}$

Estas fontes sobre as mulheres geralmente são produzidas pelos arquivos policiais ou religiosos; as vozes femininas "são ouvidas à luz dos constrangimentos impostos pelas práticas de

${ }^{22}$ ID., História das mulheres... Op. cit., pp.77-78.

${ }^{23}$ ID., IB., p. 83.

${ }^{24}$ NiCHOLSON, Linda. Interpretando o gênero. Estudos Feministas, vol. 8, $\mathrm{n}^{\circ} 2$, 2000, p.35.

${ }^{25}$ PERROT, Michelle, Práticas de memória feminina. Revista Brasileira de História. Vol. 9, nº 18, São Paulo, ago./set. 1989, p.10. 
Uma questão de gênero

poder que orientam tal e qual interrogatório". ${ }^{26}$ Dessa forma, a escolha das fontes $e$ as questões que colocamos a essas fontes devem ser repensadas, e nisso os estudos de gênero também podem contribuir para uma renovação da epistemologia da história e das ciências, não apenas humanas, mas de todas as chamadas "ciências do homem".

\section{As relações no gênero}

"Por ignorantes e pobres que sejamos, comparadas com o outro sexo", pensava, prosseguindo um raciocínio que deixara inacabado dias atrás, "armados como estão, dos pés à cabeça, privandonos até do alfabeto (...), ainda assim caem dos mastros".

Virginia Woolf, Orlando.

Não se é tão livre quanto se deseja, quanto se quer, quanto se julga, talvez quanto se vive.

Marguerite Yourcenar, Aléxis, ou o tratado do vão combate.

Joan Scott chama a atenção para a necessidade de se entender o gênero enquanto a relação entre os sexos, de como é assegurado um significado para os conceitos de homem e mulher $e$ as práticas pelas quais os significados da diferença sexual são definidos. ${ }^{27} \mathrm{O}$ gênero dá significado às distinções entre os sexos, ele "transforma seres biologicamente machos e fêmeas em homens e mulheres, seres sociais". ${ }^{28}$ Se há diferenças biológicas

${ }^{26}$ Del PRIORE, Mary, História das mulheres: as vozes do silêncio. In: FreITAS, Marcos César de. (org.) Historiografia brasileira em perspectiva. São Paulo, Contexto/EDUSF, 1998, p.227.

${ }^{27}$ ScotT, J.W. História das mulheres... Op. cit., p.89.

${ }^{28}$ Amussen, Susan Dwyer. Féminin/Masculin: le genre dans l'Angleterre de l'époque moderne. Annales ESC. Paris, vol. 40, n² 2, mar./apr., 1985, p.270. 
entre os sexos, não são elas que determinam as desigualdades entre eles. Pois as mulheres não são

obedientes, castas, perfumosas e caprichosamente enfeitadas já por natureza. Só podem conseguir essas graças, sem as quais não lhes é dado desfrutar nenhuma das delícias da vida, mediante a mais enfadonha disciplina. ${ }^{29}$

Mas a diferenciação entre os sexos pressupõe a definição do que são as características que formam a identidade do masculino $e$ do feminino. Não apenas as mulheres aprendem a ser femininas e submissas, e são controladas nisto, mas também os homens são vigiados na manutenção de sua masculinidade.

Um sistema de divisão sexual de papéis muda lentamente, freqüentemente por deslizamentos de sentido graduais. $\mathrm{E}$ isso não diz respeito apenas às mulheres; os homens devem aprender a ser dominadores $e$ ativos $e$ as mulheres a serem submissas; se as mulheres devem ser castas, os homens devem conhecer os limites nos quais eles podem atentar contra esta castidade. ${ }^{30}$

Susan Dwyer Amussen demonstra como na Inglaterra moderna o controle social sobre os papéis sexuais não afeta apenas as mulheres, mas também se faz sentir sobre os homens. $\mathrm{O}$ charivari era uma forma de humilhação pública e de coerção sobre os desviantes, de comportamentos considerados anormais sem serem necessariamente ilegais. No caso de mau comportamento da esposa, o marido também era humilhado num ritual denominado skimmington ride, no qual a fraqueza do marido é considerada como causa da falta da esposa. "Seus principais personagens são o marido e a mulher: a incapacidade

${ }^{29}$ Woolf, V. Orlando... Op. cit., p.291

${ }^{30}$ Amussen, S.D. Féminin/Masculin... Op. cit., p.271. 
Uma questão de gênero

do primeiro em controlar a segunda tem tanta importância quanto a insubmissão desta última". ${ }^{31}$ A autora observa, ainda, que a exigência de relações "normais" entre homem e mulher era necessária, na visão da sociedade, para a manutenção do equilíbrio, da "concepção da sociedade". Para isso serão cobradas as mulheres, mas também seus pais e maridos, responsáveis pela gerência do comportamento de suas esposas e filhas. ${ }^{32}$ A pergunta que deve ser feita, então, é porque a classificação do gênero comporta sempre uma hierarquia, ou seja, "que razões há que expliquem a constante estrutural de assimetria na montagem das relações entre os gêneros". "Não apenas entender o que faz com que homens e mulheres sejam vistos como essencialmente diferentes, mas porque esta diferença constitui uma hierarquização onde o masculino se impõe como superior ao feminino.

Sócrates Nolasco observa que algumas mulheres de grandes centros urbanos associam diretamente símbolos de ascensão social, profissional e de status, como carros, prestígio e poder, à expressão de seu lado masculino. Da mesma forma os homens identificam suas necessidades afetivas referindo-se ao seu suposto lado feminino. ${ }^{34}$ Alguns comportamentos são definidos pela cultura como sendo pertencentes a um ou outro sexo, aos quais o homem e a mulher "devem recalcar para serem reconhecidos como homem e mulher". ${ }^{35} \mathrm{O}$ que se configura hoje como uma liberação para os gêneros, a emancipação do homem $e$ da mulher, seria simplesmente liberar alguns aspectos masculinos da personalidade das mulheres (trabalho, produção científica, competição, esportes) e alguns (mas nunca todos) femininos da personalidade do homem (afeto, paternidade responsável,

${ }^{31}$ ID., IB., p.272.

32 ID., IB., pp.281-282.

${ }^{33}$ HeILBORN, M.L. Gênero: um olhar... Op. cit., p.46.

${ }^{34}$ NOLASCO, Sócrates. A desconstrução do masculino: uma crítica à análise de gênero. In: A desconstrução do masculino. Rio de Janeiro, Rocco, 1995, p.16.

${ }^{35}$ ID., IB., p.17. 
cuidados da casa, beleza). Daí um discurso confuso e equivocado de feministas, e de alguns homens, principalmente médicos, de que as mulheres devem se emancipar sem perder a ternura jamais, sem abandonar suas características intrinsecamente femininas, sem o risco de virarem homens. Da mesma forma se tranqüilizam os homens que se dedicar aos seus afetos ou à sua aparência não os transformará - Deus nos livre! - em mulheres.

Este discurso não só cria uma essência do que é ser homem $e$ mulher, uma identidade à qual mulheres e homens não são convidados a interferir, mas mantém intactos todos os preconceitos que diz eliminar. Assim, mulheres não devem ser homens porque elas não têm capacidade para isso, porque isso vai contra sua natureza, como dizia Sêneca, uma mulher que se faz passar por homem é um "mundo às avessas". E o homem não deve se rebaixar à condição de uma mulher, por isso ele não deve se preocupar em chorar ou demonstrar seus afetos, pois isto faz parte de seu lado feminino que pode ser expresso, porque é apenas um lado, não uma totalidade, e porque não coloca em risco sua heterossexualidade.

Dentro desta mudança consentida da masculinidade tem sido adotada uma perspectiva a partir do feminismo para compreender este fenômeno.

O esforço masculino torna-se assim, um simulacro do feminino. Institui-se a crença de que há um primeiro por meio do qual se constitui a análise de gênero, cujo centro é o feminismo. Novamente um esforço do segundo [o masculino] em tornar-se o primeiro [o feminino]. ${ }^{36}$

Esta mudança pode ser vista também como pertencendo a homens de "camadas médias mais intelectualizadas (...) inseridos numa lógica individualista de cunho fortemente psicologizante

${ }^{36}$ ID., IB., pp.23-24. 
Uma questão de gênero

(...)". ${ }^{37}$ Ela estaria então associada a um medo de "'fundir-se' à mulher e com isto perder sua "individualidade", e o medo de relacionar-se com as mulheres seria resultado de uma "fuga do sentimento de fragilidade que estas representam aos olhos deles". ${ }^{38}$ Pode ser isso também, mas repensar a masculinidade deve levar em conta as maneiras de dominação e de controle do masculino, que não são menores do que as que se exercem sobre o feminino. Os homens têm mais possibilidade de ação, mais liberdade de escolha do que as mulheres, é verdade, mas esta liberdade se exerce sob rígidos parâmetros. Se na construção da imagem do macho nordestino, por exemplo, o controle e a submissão da mulher são importantes, o controle sobre o comportamento dos homens não é menor: qualquer um que apresente um comportamento efeminado, que se vista com roupas pouco masculinas, "ou é visto freqüentemente com amigos homens e nunca com mulheres" é uma "vítima em potencial" do código de condutas que regula a masculinidade aceita $e$ reconhecida. ${ }^{39}$

E se o gênero se preocupa em escrever uma História das Mulheres, deve igualmente se ocupar de escrever uma História dos Homens, que também nunca existiu. Pois se eles estiveram sempre nos livros de história e nos arquivos, estiveram enquanto uma categoria construída social e politicamente, tanto quanto as mulheres o foram em sua ausência.

Vamos então discutir dois destes rígidos padrões que conformam a masculinidade e a feminilidade, que para mim são elementos conexos de um mesmo processo.

\footnotetext{
${ }^{37}$ LisboA, Maria Regina Azevedo. Masculinidade: as críticas ao modelo dominante e seus impasses. In: PEDRO, J.M. e GROSSI, M.P. Masculino, feminino, plural... Op. cit., p.132.

${ }^{38}$ ID., IB., p.133.

${ }^{39}$ Albuquerque JR., Durval Muniz de e Ceballos, Rodrigo. Urban Trails, Human Traps. The Construction of Territories of Pleasure and Pain in the Lives of Male Homosexuals in the Brazilian Northeast in the 1970's and 1980's. Latin American Perspectives, 122, vol. 29, n 2, march, 2002, p.322.
} 
Amílcar Torrão Filho

\section{Homossexualidade e misoginia}

A primeira conseqüência das inclinações proibidas é de nos emparedar em nós mesmos: é preciso calar, ou só falar sobre o assunto com nossos cúmplices.

Marguerite Yourcenar, Aléxis, ou o tratado do vão combate.

\section{Voltando a Joan Scott:}

A idéia de masculinidade repousa sobre a repressão necessária de aspectos femininos - do potencial bissexual do sujeito $-e$ introduz o conflito na oposição do masculino $e$ do feminino. ${ }^{40}$

De um lado, o feminino é a grande ameaça à heterossexualidade do homem; cada época define a categoria do risco, mas o feminino é sempre a ameaça ao homem. Por outro, a masculinidade é interdita à mulher, pois a mulher no lugar do homem é o "mundo às avessas", a ordem corrompida, a natureza ultrajada. Portanto, homens homossexuais rebaixam seu sexo escolhendo estar abaixo de outros homens; e as mulheres lésbicas, por sua vez, usurpam um poder que não lhes pertence, $e$ ao qual sequer podem usar, já que são desprovidas dos meios da consumação da masculinidade. Pois sendo mulher, e bela, esperase que abandone "esse fingimento de escrever $e$ meditar, $e$ [comece] a pensar ainda que seja num mateiro (e, contanto que seja num homem, ninguém se opõe a que uma mulher pense)". ${ }^{41}$

Esta visão está baseada numa identidade binária, como recorda Tânia Swain, que opõe bem e mal, boa e má sexualidade ou identidade sexual, a partir de uma "interpretação binária do mundo". ${ }^{42}$ Esta visão binária do mundo e das relações de gênero

\footnotetext{
${ }^{40}$ ScotT, J.W. Gênero como categoria... Op. cit., p.12.

${ }^{41}$ Woolf, V. Orlando... Op. cit., p.368. Destaque meu.

${ }^{42}$ SwAIN, Tânia Navarro. Para além do binário... Op. cit., pp.88-89.
} 
Uma questão de gênero

identifica o masculino e o feminino como termos opostos, ainda que complementares: eles podem conviver um com o outro, mas nunca um no outro. Os atributos considerados femininos são positivos se encontrados em mulheres, mas desqualificam os homens que os possuem, o mesmo se dando com a masculinidade em relação às mulheres. Neste caso, a natureza explica a essência de cada sexo, e perverter esta distribuição de atributos é perverter a própria natureza, sempre sábia em suas "decisões". Neste domínio do binário, as práticas e comportamentos sexuais e afetivos que não obedecem esta distinção dual serão tomadas, como desvio, perversão, "vão ser categorizadas para serem assim melhor excluídas da norma, do "normal"". ${ }^{43}$ Contra esta visão redutora, propõe a autora a inclusão da ambigüidade que o termo queer oferece, não apenas enquanto uma sexualidade alternativa, mas como

um caminho para exprimir os diferentes aspectos de uma pessoa, um espaço também para a criação e a manutenção de uma polimorfia de um discurso que desafia e interroga a heterossexualidade. ${ }^{44}$

"Homens gays são definidos quase inteiramente em termos de sua masculinidade, ou melhor, em termos de sua ausência". ${ }^{45}$ A maior ansiedade com relação à homossexualidade, para os homens, está nesta identificação com o feminino, com o ser dominado por outro homem como se fora uma mulher.

${ }^{43}$ ID., IB., p. 90.

${ }^{44}$ ID., IB., p.95. Diz a autora, ainda, que a bissexualidade, "ambigüidade assumida", pode talvez "quebrar os grilhões da prisão da sexualidade generizada, da identidade sexual, armadura invisível que nos entrava os passos no momento em que nos julgávamos livres" (p.96).

${ }^{45}$ KImmel, Michael. Manhood in America. A Cultural History. New York, Free Press, 1996, p.99. 
Amílcar Torrão Filho

Invariavelmente, questiona-se a masculinidade daquele que é penetrado, oral ou analmente, por situar-se na esfera do feminino. O homem penetrado é homem desvalorizado, é homem sem poder. Na sodomia articulam-se igualmente as forças e jogos de prazer e poder da ideologia masculina. ${ }^{46}$

Mais do que o desejo por outros homens, é o repúdio às mulheres que incomoda aos heterossexuais (inclusive as mulheres), aparecendo como a "essência" do que significa ser homossexual. Joseph Bristow argumenta que para alguns, feministas inclusas, a falta de interesse sexual nas mulheres faz os homens gays "intrinsecamente mais sexistas do que os outros homens" ${ }^{47}$ Assim, considero que a homossexualidade não apenas reclama sua entrada na história, como a história das mulheres e dos homens, mas como estas três vertentes da história constituem uma única seara. Para se compreender o feminino só é possível relacioná-lo ao masculino e vice-versa, e para entender a ambos é necessário entender a homossexualidade. A homossexualidade masculina é parte constituinte, e constitutiva, da masculinidade, o mesmo valendo para o lesbianismo em relação à feminilidade.

Em muitos lugares, principalmente na América Latina, a homossexualidade masculina é vista sob uma dupla moral. Ativos $e$ passivos são encarados de maneira diferente. Enquanto o homem que é ativo na penetração por vezes não se considera como homossexual, ou seja, não coloca em questão sua preferência pelas mulheres e sua masculinidade, o passivo é estigmatizado como detrator de seu sexo. Analisando o início do século XX, mas aparentemente válido em nossos dias, James Green observa que havia

${ }^{46}$ RAMíREZ, Rafael. Ideologias masculinas: sexualidade e poder. In: NOLASCO, S. (org.) A desconstrução do masculino... Op. cit., p.80.

${ }^{47}$ BrISTOW, Joseph. Homophobia/Misoginy: Sexual Fears, Sexual Definition. In: SHEPHERD, Simon e WALlIS, Mick. (eds.) Coming on Strong. Gay Politics and Culture. London/Boston/Sydney/Wellington, Unwin Hyman, 1989, p.66. 
Uma questão de gênero

uma inconsistência no comportamento sexual de certos indivíduos em relação ao sexo "ativo" e "passivo" [que] com freqüência desafiava o paradigma "brasileiro" que definia e categorizava o comportamento homossexual. ${ }^{48}$

Assim, alguns homens declaravam-se ativos ou passivos, mas na prática desempenhavam papéis variados. No entanto, isso não invalida a regra, pois os padrões não são contestados. Mesmo entre os homossexuais, a masculinidade $e$ a virilidade são valorizados em detrimento dos maneirismos femininos, constituindo-se como um verdadeiro valor agregado na economia da conquista sexual.

Situada em meio a uma vasta cultura heterossexual que era muito mais ignorante com relação aos gays do que hoje, este estilo de vida hipermasculino, sexualmente carregado $e$ movido a drogas, era talvez o aspecto mais visível da vida gay masculina dos anos $1970 .{ }^{49}$

Apesar de reconhecer que parte desta visão é estereotipada e resultado da ignorância em geral com relação aos estilos de vida dos homossexuais, Signorile considera que exista hoje um verdadeiro fascismo corporal (body fascism) que obriga os gays (mas não apenas eles) a serem magros, masculinos e musculosos para se manterem sexualmente atrativos e desejáveis. ${ }^{50}$

$\mathrm{Na}$ verdade, a questão de gênero que considero realmente importante com relação à atividade e passividade sexuais, diz respeito ao conceito do feminino na maior parte das sociedades.

\footnotetext{
${ }^{48}$ GREEN, James. Além do carnaval: a homossexualidade masculina no Brasil do século XX. São Paulo, Unesp, 2000, p.239. Sobre isso ver ainda FRY, Peter. Para inglês ver. Identidade e politica na cultura brasileira. Rio de Janeiro, Zahar, 1982 e PARKER, Richard. Corpos, prazeres e paixóes. A cultura sexual no Brasil contemporâneo. $2^{\text {a }}$ ed., São Paulo, Best Seller, s/d.

${ }^{49}$ Signorile, Michelangelo. Life Outside. The Signorile Report on Gay Men: Sex, Drugs, Muscles, and the Passages of Life. New York, Harper Collins, 1997, p.xix.

${ }^{50}$ ID., IB., p.28.
} 
Acredito que a homofobia é similar à misoginia, pelo menos no que diz respeito ao desprezo pelos homens sexualmente passivos ou que apresentam um comportamento feminino, independente de suas preferências sexuais, da mesma forma que sobre as mulheres que apresentam um comportamento masculinizado; aquelas que, quando amantes de mulheres casadas, representam segundo o autor latino Marcial, do século I d.C., um enigma "digno da esfinge tebana: um adultério cometido sem um homem". ${ }^{51}$

Estudando a misoginia medieval R. Howard Bloch observa que, de acordo com Fílon Judeu, autor platônico e exegeta da Bíblia do século I, o contraste entre homem e mulher é o mesmo entre a forma e a matéria, entre atividade e passividade, alma e carne. "O homem é associado com a inteligência - mens, ratio, a alma racional $-e$ a mulher com sensus, o corpo, o apetite $e$ as faculdades animais". ${ }^{52}$ Além desta relação entre a atividade, atributo masculino, racional, ordenado e positivo, e a passividade, feminina, sensual, desordenada e negativa, o feminino "que enfraquece a fibra viril da mente" 53 , Bloch afirma que a misoginia medieval, e eu acrescento a reprovação católica à sodomia, pode derivar

da redução de um modelo de sexualidade outrora mais amplo e mais livre para um de uma "normalidade" definida pela natureza, uma "heterossexualidade da reprodução", $e$ um aumento dos encargos do casal enquanto instituição. ${ }^{54}$

\footnotetext{
${ }^{51}$ MARCIAL. Epigrammes, livre I, XC, v. 1, Paris, Les Belles Lettres, p.44.

${ }^{52}$ BLoch, R. Howard, Misoginia medieval e a invenção do amor romântico. Rio de Janeiro, Editora 34, 1995, p.38. Ver SwaIN, T.N. Para além do binário..., Op. cit.: "No Ocidente, há muitos séculos, a sexualidade foi apanágio do masculino enquanto ato e do feminino enquanto locus. a mulher era o sexo - substantivo sobre o qual se estendia a sexualidade masculina - o verbo, a ação" (p.90).

${ }^{53}$ Bloch, R.H. Misoginia medieval. Op. cit., p.42.

${ }^{54}$ ID., IB., p. 100.
} 
Uma questão de gênero

Joan Scott observou que as significações de gênero e de poder se constroem reciprocamente, e que elas se fazem refletir nas condições das mulheres, independente de uma relação óbvia entre elas. ${ }^{55} \mathrm{O}$ poder se exerce sobre o gênero como forma de domínio político; por isso na base de regimes totalitários ou ditatoriais as relações de gênero são estreitamente codificadas $e$ vigiadas. Mesmo sem uma justificativa imediata e pragmática, como no caso de dissidentes políticos ou minorias étnicas $e$ religiosas, nos regimes de exceção as minorias sexuais, mulheres $e$ desviantes, são controlados e conformados a uma moral estrita. Há algo mais aí, além de simples preconceito ou desejo masculino de controle. Com relação à homossexualidade dá-se o mesmo, assim, entender as origens da interdição nos faz refletir sobre a democracia e seus limites. "A homofobia é irmã do racismo e da misoginia" 56 , e sua superação está ligada ao processo de construção da liberdade e da democracia. ${ }^{57}$

O que quero dizer é que compreender a reprovação à homossexualidade, principalmente sobre os homens passivos ou sobre as mulheres masculinizadas, é uma chave para a compreensão das principais questões do gênero. Como se constituem as desigualdades e hierarquias entre os sexos, como se constroem as identidades sexuais e como se conformam as categorias do masculino e do feminino. Como lembra Paul Veyne, a homossexualidade não é um problema em si para a história, mas sim a sua repressão:

\footnotetext{
${ }^{55}$ SCOTT, J.W. Gênero como categoria... Op. cit., p.18.

56 TORRÃo FILHO, Amílcar. Tribades galantes, fanchonos militantes. homossexuais que fizeram história. Apresentação de Ronaldo Vainfas. São Paulo, GLS/Summus, 2000, p.281.

${ }^{57}$ Não por acaso o mito de criação da democracia ateniense refere-se a dois amantes, Harmódio e Aristogitão, que lutaram contra os tiranos Hípias e Hiparco. ID., IB., pp.35-37.
} 
Amílcar Torrão Filho

Se compreende que a homofilia tenha podido perdurar tanto na Antigüidade [e em outros períodos igualmente]; é sua interdição que constitui um problema para a história. ${ }^{58}$

Estas são questões conexas que poucos autores tratam de maneira unificada e que, enquanto se insistir em vê-las de maneira estanque, não haverá uma compreensão mais sutil do problema.

Para finalizar, gostaria de chamar a atenção a uma questão já antiga nos estudos de gênero, mas que vem sendo reacendida por recentes pesquisas na área da genética humana: a relação do gênero com a biologia, das ciências humanas com as ciências da natureza.

Os estudos de gênero já mostraram como as diferenças entre os sexos, estabelecidas de maneira hierárquica, são construídas historicamente e como as noções de masculino $e$ feminino são igualmente históricas. No entanto há uma tendência muito grande em apagar os traços biológicos da constituição das identidades sexuais, que reflete em minha opinião uma relação de medo e ódio à natureza. Contra um determinismo biológico, neutralizaram-se as diferenças sexuais.

A este posicionamento radical subjaz uma visão redutoramente igualitária que, apesar de justificada como estratégia na defesa dos direitos da mulher, estaria agindo como um empecilho para o avanço do conhecimento das relações de gênero. ${ }^{59}$

No caso da homossexualidade, o medo - justificado, é verdade - de uma volta à eugenia, afasta as humanidades do

58 VeYNE, Paul. La famille et l'amour sous le haut-empire romain. Annales ESC, vol. 33, n 1, jan./fev., 1978, p.51. Sobre esta questão ver ainda BRISTOW, J. Homophobia/Misoginy... Op. cit.: "Qualquer dia destes o mundo irá descobrir o que nós já sabemos - que a homofobia e a misoginia, e não os estilos de vida dos homens gays, são os problemas centrais de nossa sociedade"(p.74).

${ }^{59}$ Carvalho, V.C. de. Gênero e artefato... Op. cit., p.15. 
Uma questão de gênero

debate sobre as relações da homossexualidade com um componente genético e adaptativo. Jim McKnight, um psicólogo australiano, observa que o processo evolutivo é igualmente biológico e social, e que um suposto gene da homossexualidade, como proposto pelo cientista Dean Hamer, daria conta de um dos aspectos da homossexualidade, não da homossexualidade em sua totalidade. ${ }^{60}$ Diz este autor que:

afirmar que a homossexualidade, como um processo biológico, é comportamentalmente baseada, não invalida uma racionalidade evolutiva, mas como vimos, pode ser mais confortante admitir que ela é parte de nossa mensagem genética e, assim, indiscutivelmente parte de nossa história evolutiva. ${ }^{61}$

Dessa forma, a homossexualidade é parte da estratégia de sobrevivência da espécie, o que muda uma chave para a sua compreensão: mais importante do que saber o que "causaria" a homossexualidade, seria saber, de um ponto de vista evolutivo, o que permite que ela sobreviva. ${ }^{62} \mathrm{~A}$ variabilidade genética, fundamental à sobrevivência pode ser uma das respostas; outra sugere que a

homossexualidade humana se originou em função da importância cada vez maior da cooperação masculina, começando com o reconhecimento de territórios, passando

\footnotetext{
${ }^{60}$ McKNIGHT, Jim. Straight Science? Homosexuality, Evolution and Adaptation. London/New York, Routledge, 1997, pp.14-15. Sobre Dean Hamer e sua pesquisa sobre um tipo específico de homossexualidade, pp.58 e ss., ver ainda TORRÃO FILHO, A., Tribades galantes... Op. cit., pp.216-219.

${ }^{61}$ McKNiGHT, J. Straight Science?... Op. cit., p.44.

${ }^{62}$ ID., IB., p.149.
} 
Amílcar Torrão Filho

pelas hierarquias de dominância, e terminando com

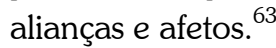

A história $e$ as ciências humanas em geral podem dar às ciências da natureza e exatas uma dimensão ética e uma compreensão histórica, que podem evitar transformar suas descobertas em ideologias de controle ou em falsas compreensões da natureza humana, daí a importância de uma maior interação entre elas.

Vim ao sexo e à biologia, para sair deles. Pois considero que devemos dar atenção a eles, não termos repugnância à natureza, sem contudo fazermos dela uma criadora de essências $e$ identidades, sem transferir a ela nossas noções morais. Também devemos entender a homossexualidade para além do sexo: dentro da homossexualidade (e da sexualidade em geral) há afeição, amor e amizade. A amizade, aliás, esteve sempre muito ligada ao amor, na Antigüidade, onde os amantes eram denominados amigos, nas canções medievais, as Cantigas de Amigo, no francês moderno e seu petit(e) ami(e), e inúmeros outros exemplos. ${ }^{64}$ Por isso creio ser equivocado querer substituir o termo homossexualidade, que em seu sentido primeiro foi criado pelo médico alemão Karoly Maria Benkert (ou Kertbény) para substituir o termo sodomia, eivado de preconceitos religiosos, numa petição que ele apresentou ao parlamento alemão pedindo a supressão da lei que penalizava a homossexualidade, por um termo como o

${ }^{63}$ WERNER, Dennis. Sobre a evolução e variação cultural na homossexualidade masculina. In: PEDRo, J.M. e Grossi, M.P. (orgs.) Masculino, feminino, plural... Op. cit., p.116.

${ }^{64} \mathrm{Cf}$. Boswell, John. Christianisme, tolérance sociale et homosexualité. Les homosexuels en Europe occidentale des débuts de l'ére chrétienne au XIVe. siècle. Paris, Gallimard, 1985, pp.75-76. "É de fato provável que as sociedades antigas não tenham marcado uma diferença tão grande entre 'amizade' e 'amor' romântico (romance) quanto as sociedades modernas". Ver do mesmo autor Hacia um enfoque amplio. Revoluciones universales y categorías relativas a la sexualidad. In: STEINER, George e BOYERS, Robert. (orgs.) Homosexualidad: literatura y política. Madrid, Alianza, 1982, pp.38-74. 
Uma questão de gênero

homoerotismo, que a reduz a meras relações sexuais. John Boswell introduziu na história da homossexualidade o termo gay, que o autor observa como designativo de relações entre homens desde o século XIII, com origem no provençal antigo. ${ }^{65}$ Michel Foucault acredita que este conceito introduzido por Boswell, em lugar de homossexual, proporciona um útil instrumento de investigação, além de contribuir para "uma valoração positiva (...) de um tipo de consciência na qual a afetividade, o amor, o desejo $e$ a relação sexual interpessoais ganham uma decidida importância" ${ }^{66}$ Prefiro também, já que, filhos de Adão, temos de dar nomes, um termo como o cunhado por Paul Hardman, homoaffectionalism, designando relações entre pessoas do mesmo sexo que não necessariamente envolvem atos sexuais, mas que são caracterizadas por um forte vínculo emocional $e$ que reconhece "o fenômeno do mútuo altruísmo entre indivíduos do mesmo gênero como a base do apoio mútuo, lealdade $e$ cooperação necessários para permitir o desenvolvimento da civilização". ${ }^{6}$

${ }^{65}$ ID., IB., pp.70-71.

${ }^{66}$ FouCAULT, Michel. Opción sexual y actos sexuales: una entrevista realizada por James O'Higgins. In: STEINER, G., BOYERS, R. (orgs.) Homosexualidad... Op. cit., p. 17.

${ }^{67}$ Hardman, Paul D., Homoaffectionalism. Male Bonding from Gilgamesh to the Present. San Francisco, GLB, 1993, pp.v-vi. Ver também p.227. 